\title{
New high-performance porous ionic liquids for low pressure $\mathrm{CO}_{2}$ capture
}

\author{
Jocasta Avila, $^{\dagger}$ L. Fernando Lepre, ${ }^{\dagger}$ Catherine S. Santini, $^{\ddagger}$ Martin Tiano, ${ }^{\dagger}$ \\ Sandrine Denis-Quanquin, ${ }^{\dagger}$ Kai Chung Szeto, ${ }^{\ddagger}$ Agilio A. H. Padua, ${ }^{\dagger}$ and \\ Margarida Costa Gomes*, $\uparrow$ \\ †Laboratoire de Chimie de l'ENS Lyon, CNRS and Université de Lyon, 46 allée d'Italie, \\ 69364 Lyon, France \\ $\ddagger$ University of Lyon, CPE Lyon, CNRS, UMR 5265, Chemistry, Catalysis, Polymers and \\ Processes (C2P2), 43 Bvd. Du 11 Novembre 1918, F-69616 Villeurbanne, France \\ E-mail: margarida.costa-gomes@ens-lyon.fr
}

\begin{abstract}
Porous ionic liquids are non volatile, versatile materials that associate porosity and fluidity. New porous ionic liquids, based on the ZIF-8 metal-organic framework and on phosphonium acetate or levulinate salts, were prepared and show an increased capacity to absorb carbon dioxide at low pressures. Porous suspensions based on phosphonium levulinate ionic liquid absorb reversibly $103 \%$ more carbon dioxide per mass than pure ZIF-8 per mass at 1 bar and $303 \mathrm{~K}$. We show how the rational combination of MOFs with ionic liquids can greatly enhance low pressure $\mathrm{CO}_{2}$ absorption, paving the way toward a new generation of high-performance, readily available liquid materials for effective low pressure carbon capture.
\end{abstract}




\section{Introduction}

Materials combining the properties of liquids and porous solids, such as fluidity and permanent porosity, are receiving growing attention from academia and industry since the discovery of porous liquids in $2007 .{ }^{1}$ These polyfunctional materials open a wide range of possibilities in materials and process development, including potential applications in separations, catalysis and drug delivery. ${ }^{2}$

Porous liquids can be obtained by functionalizing porous solid materials or by dissolving them in sterically hindered solvents, leading to type I and type II porous liquids, respectively. ${ }^{2-5}$ An alternative approach consists in suspending porous solid materials in voluminous solvents to form type III porous liquids. ${ }^{6-10}$ These last were successfully prepared by mixing metal-organic frameworks (MOF) with ionic liquids to form stable suspensions that remain liquid at ambient conditions. These suspensions have been designated as porous ionic liquids as they maintain typical features of both the porous solid and the liquid salt. ${ }^{6,11}$ So far, voluminous phosphonium-based ionic liquids, such as trihexyltetradecylphosphonium bis(trifluoromethylsulfonyl)imide, $\left[\mathrm{P}_{6,6,6,14}\right]\left[\mathrm{NTf}_{2}\right]$, and trihexyltetradecylphosphonium chloride, $\left[\mathrm{P}_{6,6,6,14}\right][\mathrm{Cl}]$, have succeeded in stabilizing and maintaining the permanent porosity of both ZIF-8 and HKUST-1 (a zinc methylimidazolate and a copper benzene-1,3,5-carboxylate MOF, respectively) forming porous ionic liquids characterized by a significantly increased, yet non-selective, physisorption of carbon dioxide, nitrogen and methane. ${ }^{6,11}$

One of the most appealing features of ionic liquids is the possibility of combining anions and cations, including reactive groups, to tune their physical and chemical properties. ${ }^{12}$ Ionic liquids are practically non-volatile and so their use can decrease the costs of gas separation processes, namely for solvent regeneration, while also reducing the emissions of volatile and toxic chemicals. ${ }^{13}$ Ionic liquids containing amino-functionalized cations ${ }^{14}$ or aproticheterocyclic ${ }^{15}$ or carboxylate anions ${ }^{13,16,17}$ can react with carbon dioxide and have been successfully tested as high capacity liquid gas sorbents for carbon capture processes. ${ }^{18}$

We have prepared new porous ionic liquids based on voluminous phosphonium cations 
and carboxylate anions and tested them as liquid sorbents for carbon dioxide at low pressures. So far, studies involving chemisorption of gases using fluid porous ionic liquids have not been reported. We believe that if permanent porosity can be added to ionic liquids capable of reversibly reacting with carbon dioxide, ${ }^{13,16,17}$ their capacity could be further intensified. Imidazolium acetate ionic liquids are known for their ability to chemically absorb relatively large amounts of carbon dioxide through a reversible reaction between the gas and the imidazolium cation. ${ }^{16,17}$ Phosphonium acetate ionic liquids can also absorb carbon dioxide chemically, ${ }^{19}$ so phosphonium carboxylate salts are probably good candidates to make reactive, porous ionic liquids. In this work we verify the presence of permanent porosity in suspensions of ZIF-8, a previously tested MOF in different phosphonium carboxylate ionic liquids, and we study the role played by the cation and the anion in the carbon dioxide absorption mechanism.

\section{Experimental}

\section{Materials}

The ionic liquids tetrabutylphosphonium acetate, $\left[\mathrm{P}_{4,4,4,4}\right][\mathrm{OAc}]$, and tetrabutylphosphonium levulinate, $\left[\mathrm{P}_{4,4,4,4}\right][\mathrm{Lev}]$, were both synthesized and characterized as described in the Suplementary Information. The ionic liquid trihexyltetradecylphosphonium bis(trifluoromethyl sulfonylamide), $\left[\mathrm{P}_{6,6,6,14}\right]\left[\mathrm{NTf}_{2}\right]$, was purchased from Iolitec $>98 \%$ pure. Tetrabutylphosphonium hydroxide $\left[\mathrm{P}_{4,4,4,4}\right][\mathrm{OH}]$, was purchased as a $40 \%$ wt. solution in water from Sigma Aldrich. Before use, the $\left[\mathrm{P}_{4,4,4,4}\right][\mathrm{OAc}],\left[\mathrm{P}_{4,4,4,4}\right][\mathrm{Lev}]$ and $\left[\mathrm{P}_{6,6,6,14}\right]\left[\mathrm{NTf}_{2}\right]$ ionic liquids were degassed for at least $72 \mathrm{~h}$ under a primary vacuum and kept dried and degassed before the preparation of the ionic liquids mixtures and of the porous liquids. Acetic acid $\geq 99 \%$ and levulinic acid $\geq 97 \%$ were both purchased from Sigma Aldrich and used without further purification. ZIF-8, a 2-methylimidazole zinc salt $\left(\mathrm{ZnIm}_{2}\right)$ with a pore aperture of $3.4 \AA$ and a pore diameter of $11.6 \AA$ - Basolite Z1200 (BASF product 691348 ) — was obtained from 
Sigma Aldrich, batch STBG590V. The solid was passed through a $11 \mu \mathrm{m}$ pore Nylon Nitex sieve to reduce the distribution of solid particle sizes in the porous liquid. Carbon dioxide, $\mathrm{CO}_{2} 4.5$, was purchased from Messer with a mole fraction purity of $99.995 \%$ and used as received.

\section{Sample preparation}

The ionic liquid samples used are listed in Table 1. The ionic liquid mixtures were prepared by weighting the components using a New Classic MS Mettler Toledo balance with an accuracy of $\pm 0.01 \mathrm{mg}$ inside a glove box GP(campus) Jacomex.

Table 1: Sample nomenclature and composition of the ionic liquids and the ionic liquids mixtures

\begin{tabular}{llccc}
\hline Sample & Chemicals & $m_{\mathrm{IL} 1}(\mathrm{~g})$ & $m_{\mathrm{IL} 2}(\mathrm{~g})$ & $\chi(\mathrm{IL} 2)$ \\
\hline IL1 & {$\left[\mathrm{P}_{6,6,6,14}\right]\left[\mathrm{NTf}_{2}\right]$} & - & - & - \\
$\mathrm{IL} 2$ & {$\left[\mathrm{P}_{4,4,4,4}\right][\mathrm{OAAc}]$} & - & - & - \\
$\mathrm{IL} 3$ & {$\left[\mathrm{P}_{4,4,4,4}\right][\mathrm{Lev}]$} & - & - & - \\
$\mathrm{IL}_{0.75} \mathrm{IL} 2_{0.25}$ & {$\left[\mathrm{P}_{6,6,6,14}\right]\left[\mathrm{NTf}_{2}\right]_{0.75}\left[\mathrm{P}_{4,4,4,4}\right][\mathrm{OAc}]_{0.25}$} & 4.04216 & 0.56097 & 0.24958 \\
$\mathrm{IL}_{0.5} \mathrm{IL} 2_{0.5}$ & {$\left[\mathrm{P}_{6,6,6,14}\right]\left[\mathrm{NTf}_{2}\right]_{0.5}\left[\mathrm{P}_{4,4,4,4}\right][\mathrm{OAAc}]_{0.5}$} & 3.08371 & 1.25800 & 0.49435 \\
$\mathrm{IL}_{0.25} \mathrm{LL} 2_{0.75}$ & {$\left[\mathrm{P}_{6,6,6,14}\right]\left[\mathrm{NTf}_{2}\right]_{0.25}\left[\mathrm{P}_{4,4,4,4}\right][\mathrm{OAc}]_{0.75}$} & 1.93509 & 2.42761 & 0.75040 \\
\hline
\end{tabular}

The porous liquids, suspensions of ZIF-8 in the IL1, IL2, IL1 $1_{0.75} \mathrm{IL}_{0.25}, \mathrm{IL}_{0.5} \mathrm{IL} 2_{0.5}$, IL $1_{0.25}$ IL $2_{0.75}$ and IL3, were prepared at room temperature by weighing the components using a New Classic MS Mettler Toledo balance with an accuracy of $\pm 0.01 \mathrm{mg}$, and by stirring the mixture at $430-540 \mathrm{~min}^{-1}$ during $5 \mathrm{~min}$. The porous liquids were degassed under primary vacuum for up to $24 \mathrm{~h}$ before use. The porous liquids prepared are listed in Table 2 , the uncertainty on the suspended solid concentration being estimated as $\pm 0.0005 \%$.

\section{Density and viscosity}

Density and viscosity were measured in a coupled Anton Paar density meter (DMA 5000 M) and viscometer (LOVIS $2000 \mathrm{ME}$ ) in the temperature range 293-353 K at atmospheric 
Table 2: Sample nomenclature and composition of the porous liquids

\begin{tabular}{|c|c|c|c|c|}
\hline Sample & Chemicals & $m_{\mathrm{IL}}(\mathrm{g})$ & $m_{\mathrm{MOF}}(\mathrm{g})$ & $\mathrm{MOF} \% \mathrm{w} / \mathrm{w}$ \\
\hline PoIL1-Z5 & $\mathrm{IL} 1+\mathrm{ZIF}-8$ & 2.01215 & 0.09983 & 4.9614 \\
\hline $\mathrm{Po}\left(\mathrm{IL}_{0.75} \mathrm{IL}_{0.25}\right)-\mathrm{Z} 5$ & $\mathrm{IL}_{0.75} \mathrm{IL} 2_{0.25}+$ ZIF-8 & 1.91275 & 0.09564 & 5.0001 \\
\hline $\mathrm{Po}\left(\mathrm{IL} 1_{0.5} \mathrm{IL} 2_{0.5}\right)-\mathrm{Z} 5$ & $\mathrm{IL}_{0.5} \mathrm{IL}_{0.5}+\mathrm{ZIF}-8$ & 1.99626 & 0.09977 & 4.9978 \\
\hline $\operatorname{Po}\left(\mathrm{IL} 1_{0.25} \mathrm{IL}_{0.75}\right)-\mathrm{Z} 5$ & $\mathrm{IL}_{0.25} \mathrm{IL}_{0.75}+$ ZIF-8 & 1.99327 & 0.10014 & 5.0239 \\
\hline PoIL3-Z5 & $\mathrm{IL} 3+\mathrm{ZIF}-8$ & 2.51755 & 0.12335 & 4.8996 \\
\hline
\end{tabular}

pressure. The densimeter's measuring element is a U-shaped vibrating-tube, that is electronically excited to oscillate at its characteristic frequency whose value changes depending on the density of the filled sample. The true density of the sample is determined via a precise measurement of the characteristic frequency. The calibration of the equipment was performed before the measurements with two substances of the precisely known densities, air and the Anton Paar density standard ultra-pure water. Even if the densimeter is only recommended for the measurement of homogeneous fluid samples, we believe that in the present case, the density of the stable suspensions is also precise to within $5 \times 10^{-5} \mathrm{~g} \mathrm{~cm}^{-3}$ as a function of the temperature controlled to within $0.001^{\circ} \mathrm{C}$.

The viscometer is based on Hoeppler falling ball principle, measuring the rolling time of a ball through the liquid confined in a glass capillary. In order to cover the samples viscosity in the worked temperature range, two capillaries with different diameter, 1.8 and $2.5 \mathrm{~mm}$, were calibrated with two different standard oils, APN26 and APN415 respectively, and two balls with known material, geometry and density. The precision of this module is $0.05 \%$ in the viscosity and $0.02^{\circ} \mathrm{C}$ in the temperature. Both the densimeter and viscometer cells were filled with ca. $1 \mathrm{~mL}$ of sample and the measurements were carried out simultaneously, using the temperature table scan mode. 


\section{Gas absorption}

Gas solubilities were measured by a gravimetric method using an Intelligent Gravimetric Analyzer (IGA001) from Hiden Analytical in the 0.5-5 bar pressure range at $303 \mathrm{~K}$. The gravimetric experiments were carried out as extensively described previously. ${ }^{11}$ Essentially, the samples are loaded into the microbalance and are degassed at secondary vacuum up to $24 \mathrm{~h}$ before starting several cycles of absorption/desorption for each temperature, which are automatic controlled by the equipment software. The mass of gas absorbed, $m_{g}$, at each pressure and temperature was obtained from the raw weight data, $m_{\text {reading, }}$ using equation (1).

$$
m_{\text {reading }}=m_{s}+m_{g}+m_{g}^{\mathrm{EP}}-\sum_{i} \frac{m_{i}}{\rho_{i}} \rho_{g}\left(T_{i}, p\right)+\sum_{j} \frac{m_{j}}{\rho_{j}} \rho_{g}\left(T_{j}, p\right)-\frac{m_{s}}{\rho_{s}\left(T_{s}\right)} \rho_{g}\left(T_{s}, p\right)
$$

where $m_{s}$ is the mass of degassed sample, $m_{g}^{\mathrm{EP}}$ the effect due to adsorbed gas on the balance components (determined by performing a blank measurement), and the sums over the $i$ and $j$ components account for the respective buoyancy effects, on the sample and counterweight sides, respectively. Components may be at different temperatures as specified in Table S1. The effect of the gas dissolved for the calculation of the buoyancy effect (last term in equation (1)) was considered negligible.

A blank measurement performed with an empty cell but in the same pressure and temperature conditions as the measured samples is used to determine the necessary corrections:

$$
\begin{aligned}
m_{\text {reading }}^{\mathrm{EP}} & =m_{0}+m_{g}^{\mathrm{EP}}-\sum_{i} \frac{m_{i}}{\rho_{i}} \rho_{g}\left(T_{i}, p\right)+\sum_{j} \frac{m_{j}}{\rho_{j}} \rho_{g}\left(T_{j}, p\right) \\
& =m_{0}+A p
\end{aligned}
$$

where $m_{0}$ is initially recorded by the IGA balance software during the empty run, and zeroed by the software (tare) before starting the isotherms with sample. 
The quantity of gas absorbed at each temperature and pressure per mass of liquid, $b(p, T)$ is calculated as:

$$
b(p, T)=\frac{\left(m_{g} / M w\right)}{m_{s}}
$$

\section{NMR measurements}

NMR experiments were carried out in the pure ionic liquids, $\left[\mathrm{P}_{4,4,4,4}\right][\mathrm{OAc}]$ and $\left[\mathrm{P}_{4,4,4,4}\right][\mathrm{Lev}]$, before and after contact with $\mathrm{CO}_{2}$. The pure ionic liquid was first degassed and dried under primary vacuum $(<0.1$ mbar $)$ during 72 hours at $353 \mathrm{~K}$ for $\left[\mathrm{P}_{4,4,4,4}\right][\mathrm{OAc}]$ and at $313 \mathrm{~K}$ for $\left[\mathrm{P}_{4,4,4,4}\right][\mathrm{Lev}]$. The liquids were then transferred to a high pressure NMR tube and degassed again over $48 \mathrm{~h}$ at the same temperatures. Prior to degassing, sealed glass capillaries containing DMSO-d6 for $\left[\mathrm{P}_{4,4,4,4}\right][\mathrm{OAc}]$ and $\mathrm{C}_{6} \mathrm{D}_{6}$ for $\left[\mathrm{P}_{4,4,4,4}\right][\mathrm{Lev}]$ was inserted in the NMR high-pressure tube to act as internal references, respectively.

${ }^{1} \mathrm{H},{ }^{31} \mathrm{P},{ }^{13} \mathrm{C}$, COSY, HSQC, HMBC NMR spectra were measured in a Bruker Avance 400 $\mathrm{MHz}$ spectrometer with a Prodigy probe at $342 \mathrm{~K}$ for $\left[\mathrm{P}_{4,4,4,4}\right][\mathrm{OAc}]$ with or without $\mathrm{CO}_{2}$, and at $323 \mathrm{~K}$ for $\left[\mathrm{P}_{4,4,4,4}\right][\mathrm{Lev}]$ with or without $\mathrm{CO}_{2}$. After recording the spectra for the pure ionic liquids under vacuum $(p \sim 0.1$ bar $)$, the same samples were left under a pressure of 10 bar of $\mathrm{CO}_{2}$ at $342 \mathrm{~K}$ for $\left[\mathrm{P}_{4,4,4,4}\right][\mathrm{OAc}]$ and 20 bar of $\mathrm{CO}_{2}$ at $313 \mathrm{~K}$ for $\left[\mathrm{P}_{4,4,4,4}\right][\mathrm{Lev}]$ for several days until no pressure drop was observed after closing the gas cylinder. A digital pressure gauge with an accuracy of \pm 0.4 bar was used to control the gas pressure. ${ }^{1} \mathrm{H},{ }^{31} \mathrm{P}$ and ${ }^{13} \mathrm{C}$ NMR spectra of the $\mathrm{CO}_{2}$ solutions were then collected using the same conditions as that used for the pure ionic liquids.

\section{Infrared measurements}

The infrared spectra of $\left[\mathrm{P}_{6,6,6,14}\right]\left[\mathrm{NTf}_{2}\right],\left[\mathrm{P}_{4,4,4,4}\right][\mathrm{OAc}]$ and its mixtures were collected in the attenuated total reflection mode (ATR) of a Perkin Elmer Spectrum 65 FT-IR spectrometer. A droplet of each sample (IL1, IL $1_{0.75} \mathrm{IL} 2_{0} .25, \mathrm{IL}_{0.5} \mathrm{IL} 2_{0} .5$ and $\left.\mathrm{IL} 1_{0.25} \mathrm{IL} 2_{0} .75\right)$ and a small 
amount of solid (IL2) was placed on top of the ATR crystal, and the measurements were performed in order to accumulate 64 scans in the wave number range of $515-4000 \mathrm{~cm}^{-1}$ with $2 \mathrm{~cm}^{-1}$ of resolution.

The infrared spectra of $\left[\mathrm{P}_{4,4,4,4}\right][\mathrm{Lev}]$ under $\mathrm{CO}_{2}$ pressure were obtained in an integrated system comprising mass flow controllers (Brooks), FT-IR adapted high temperature, airtight reaction chamber (Harrick Scientific) with a 4-way valve and a pressure regulating valve. The reaction chamber was equipped with ZnSe windows and fitted into the Praying Mantis optical unit also provided by Harrick. A film of the ionic liquid was deposited onto a silicon wafer in an Ar-filled glovebox. All the lines were extensively purged before $\mathrm{CO}_{2}$ was introduced in the chamber. The FTIR spectra were collected in a Thermo Scientific FTIR 6700 spectrophotometer in diffuse reflectance mode equipped with a MCT detector. A spectrum comprises 64 scans and was recorded continuously at $4 \mathrm{~cm}^{-1}$ resolution at room temperature up to 10 bar.

\section{Results and Discussion}

The $\mathrm{CO}_{2}$ absorption capacity of the synthesized tetrabutylphosphonium acetate, $\left[\mathrm{P}_{4,4,4,4}\right][\mathrm{OAc}]$, was gravimetrically measured at $343 \mathrm{~K}$. $\left[\mathrm{P}_{4,4,4,4}\right][\mathrm{OAc}]$ is a solid at room temperature having a melting point at $327.5 \mathrm{~K} .{ }^{20}$ The experimental results depicted in Figure 1 reveal a considerable hysteresis between absorption and desorption isotherm cycles probably due to a slow diffusivity of the gas. Average values with the corresponding uncertainties were considered within this work. The experimental data are listed in detail in Supplementary Tables S2-S3. Table S2 shows the raw data, whereas Table S3 shows the average between absorption an desorption cycles for each isotherm with the respective uncertainty in temperature, pressure and gas solubility.

The isotherm in Figure 1 shows that $\mathrm{CO}_{2}$ absorption capacity is not linearly dependent with pressure, suggesting that the gas is chemically absorbed by $\left[\mathrm{P}_{4,4,4,4}\right][\mathrm{OAc}]$. Indeed, 


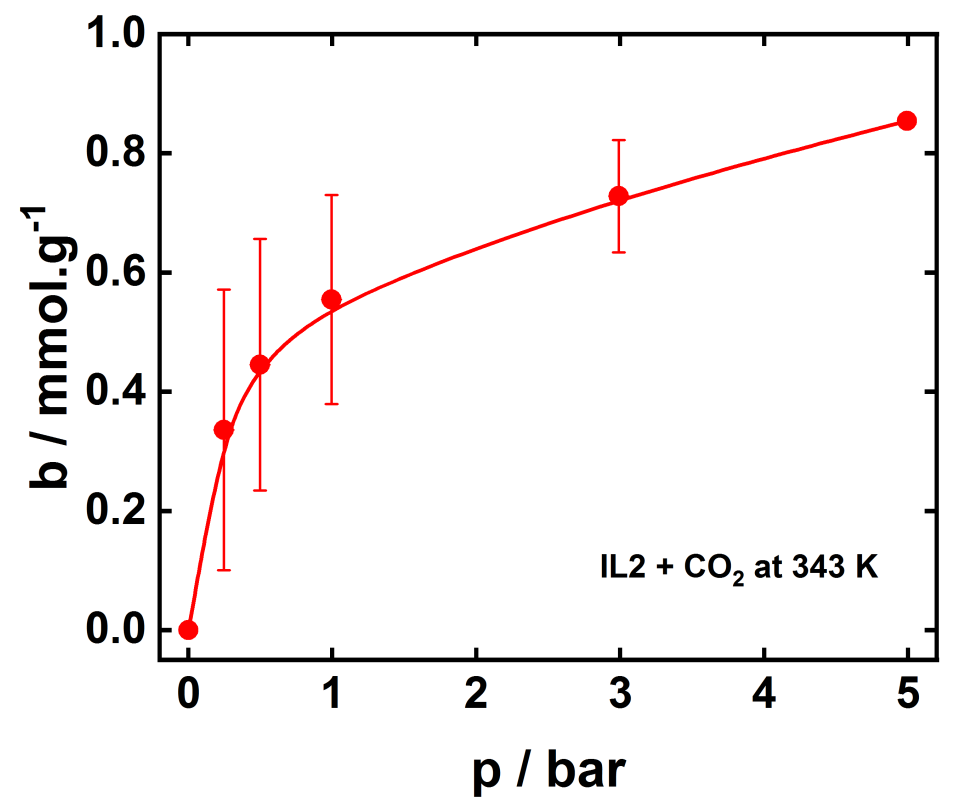

Figure 1: $\mathrm{CO}_{2}$ Absorption by $\left[\mathrm{P}_{4,4,4,4}\right][\mathrm{OAc}]$ in the pressure range of $0-5$ bar at $343 \mathrm{~K}$.

chemical reactions between $\mathrm{CO}_{2}$ and tetraalkylphosphonium-based ionic liquids have already been reported when phosphonium cations are paired with basic anions such as azolides ${ }^{19}$ or phenolates. ${ }^{21}$ In the presence of $\mathrm{CO}_{2}$ these basic anions are capable of stabilizing the most acidic proton in the $\alpha$-carbon of the tetraalkylphosphonium cation and a proton transfer can occur. The corresponding acid of the anion is formed as well as an ylide species that is subsequently trapped with $\mathrm{CO}_{2}$ (Figure 2). The ylide generation from phosphonium-based ionic liquids has been used as Wittig reagents ${ }^{22}$ or reaction catalysts. ${ }^{23}$

Concerning the acetate anion, it is long known that it is basic enough to abstract the acid proton from imidazolium cations and lead to a chemical reaction between imidazolium-based acetate ionic liquids and $\mathrm{CO}_{2} \cdot{ }^{16,17}$ Therefore, one could expect that the basicity of the acetate anions can also lead to a carboxylation at the $\alpha$ - carbon atom of tetraalkylphosphonium acetate cations.

In order to study the $\mathrm{CO}_{2}$ absorption mechanism in $\left[\mathrm{P}_{4,4,4,4}\right][\mathrm{OAc}]$, NMR spectroscopic experiments were performed before and after $\mathrm{CO}_{2}$ absorption. The ${ }^{31} \mathrm{P}$ NMR spectra in 


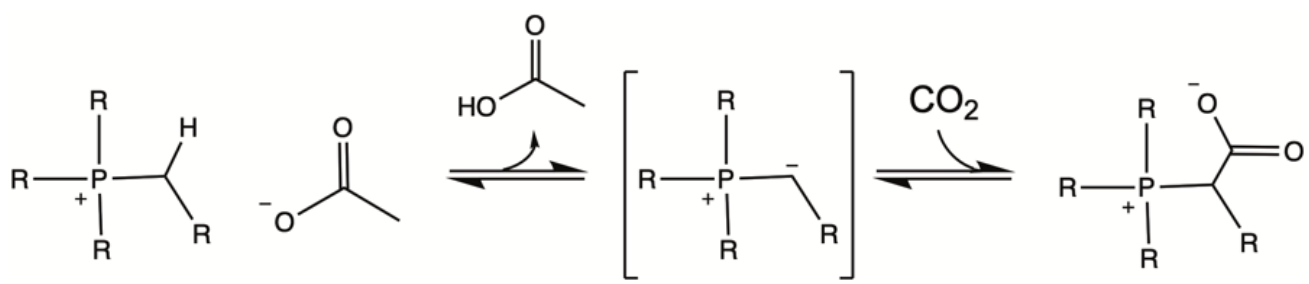

Figure 2: Mechanism of $\mathrm{CO}_{2}$ absorption by a tetraalkylphosphonium acetate ionic liquid.

Figure 3 shows two different phosphonium environments after $\mathrm{CO}_{2}$ absorption at 10 bar and $342 \mathrm{~K}$. The new peak at $30.75 \mathrm{ppm}$ reveals that $\mathrm{CO}_{2}$ reacts with the phosphonium cation and a new species is generated. In fact, Gohndrone et al. ${ }^{19}$ observed a similar peak for the ionic liquid $\left[\mathrm{P}_{6,6,6,14}\right][2-\mathrm{CNpyr}]$ after $\mathrm{CO}_{2}$ absorption at 3 bar and $333 \mathrm{~K}$. The peaks at $c a$. $37.2 \mathrm{ppm}$ and at ca. $44.3 \mathrm{ppm}$ are present both before and after contact with $\mathrm{CO}_{2}$ and can be assigned to the presence of oxide impurities. The ${ }^{1} \mathrm{H}$ NMR spectrum in Figure 3 shows a new broad peak at $c a$. $16.1 \mathrm{ppm}$, corresponding to the acidic proton $(\mathrm{COOH})$ of a carboxylic acid. Precise analysis of ${ }^{1} \mathrm{H},{ }^{13} \mathrm{C}$ NMR spectra, together with HSQC and COSY 2D NMR experiments, confirmed the formation of a zwitterionnic adduct by the condensation of $\mathrm{CO}_{2}$ onto $\left[\mathrm{P}_{4,4,4,4}\right]$, as well as the protonation of acetate anion in acetic acid. (Details are given in Supplementary Information).

Since $\left[\mathrm{P}_{4,4,4,4}\right][\mathrm{OAc}]$ is solid at room temperature, mixtures with another phosphonium based ionic liquid, $\left[\mathrm{P}_{6,6,6,14}\right]\left[\mathrm{NTf}_{2}\right]$, were prepared in order to be able to work with a liquid in a wider range of temperature. The addition of $\left[\mathrm{P}_{4,4,4,4}\right][\mathrm{OAc}]$ (IL2) to $\left[\mathrm{P}_{6,6,6,14}\right]\left[\mathrm{NTf}_{2}\right]$ (IL1) lead to homogeneously stable mixtures at room temperature in the range of $\left[\mathrm{P}_{4,4,4,4}\right][\mathrm{OAc}]$ mole fraction compositions, $0.25 \leq \chi($ IL2) $\geq 0.75$. The mixtures were characterized by determining their densities and viscosities that are reported in Tables S4-S5 and Figure S3. The interactions between the components of the mixture and their deviations from ideal behavior were studied using infrared spectroscopy and by determining their excess molar properties (Figure S3-S5). No strong, specific interaction was found in the mixtures and no effect of the proximity of the ions due an efficient packing in the mixtures could be detected (details are included in Supplementary Information). 

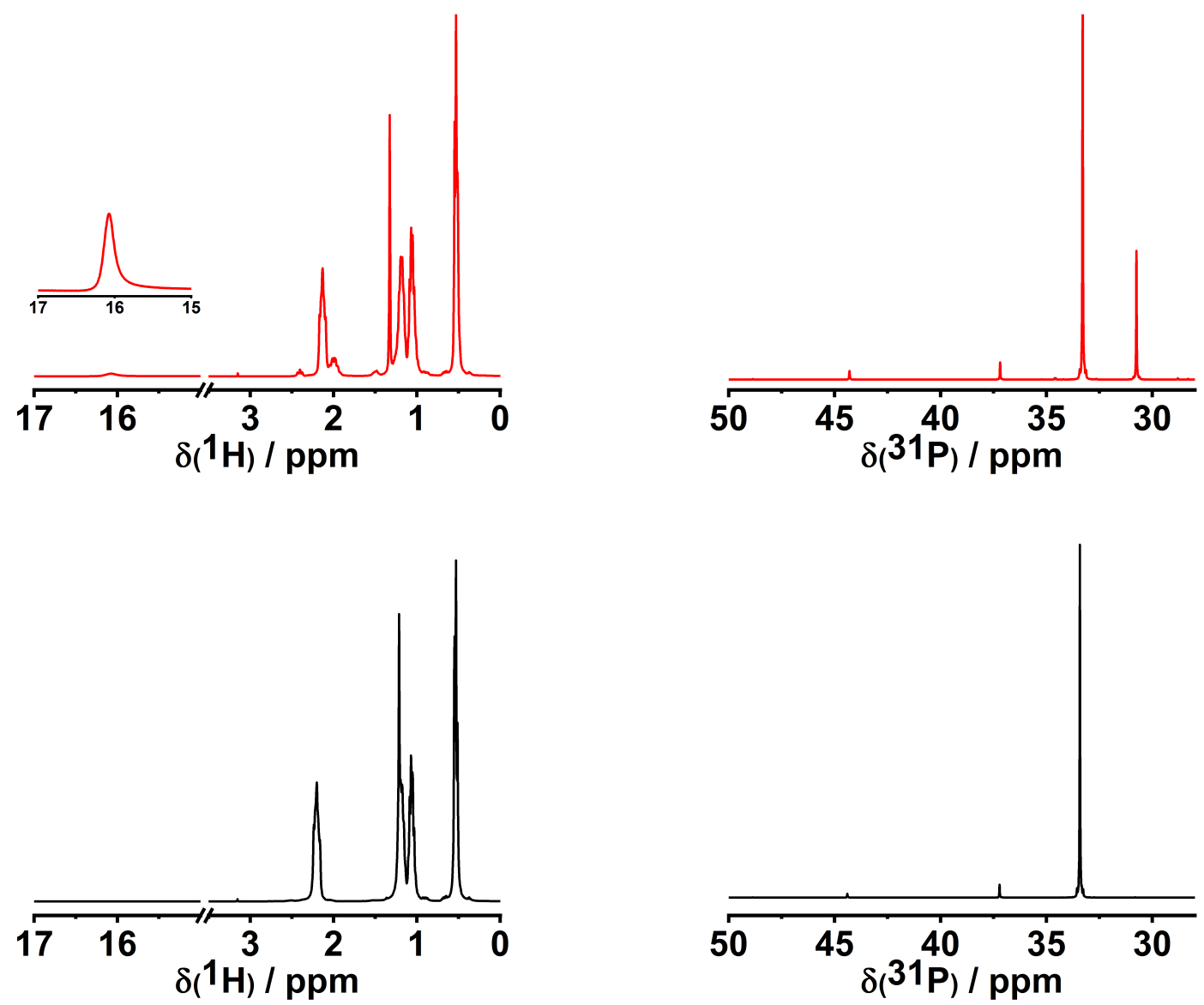

Figure 3: ${ }^{1} \mathrm{H}$ (left) and ${ }^{31} \mathrm{P}$ (right) NMR spectra of $\left[\mathrm{P}_{4,4,4,4}\right][\mathrm{OAc}]$ before (black line) and after (red line) $\mathrm{CO}_{2}$ absorption at $342 \mathrm{~K}$. The ${ }^{1} \mathrm{H}$ highlighted peak at $c a .16 \mathrm{ppm}$ corresponds to the acidic proton $(\mathrm{COOH})$ of acetic acid $\left(\mathrm{H}_{3} \mathrm{CCOOH}\right)$ produced.

Since all the mixtures are liquid at room temperature, the gas absorption measurements could be performed at $303 \mathrm{~K}$. The results are presented in Figure 4 and Supplementary Tables S2-S3. All the mixtures are able to absorb significant larger quantities of carbon dioxide than pure $\left[\mathrm{P}_{6,6,6,14}\right]\left[\mathrm{NTf}_{2}\right]$, the absorption capacity increasing with the increase of concentration in phosphonium acetate. As previously observed for $\left[\mathrm{P}_{4,4,4,4}\right][\mathrm{OAc}]$ (Figure 1), $\mathrm{CO}_{2}$ absorption does not vary linearly with pressure for all mixtures, pointing towards a chemical reaction of the gas with the mixtures even in the sample with lower $\left[\mathrm{P}_{4,4,4,4}\right][\mathrm{OAc}]$ mole fraction, $\operatorname{IL} 1_{0.75} \mathrm{IL} 2_{0.25}$.

We have followed our previous approach to prepare porous ionic liquids based on the 


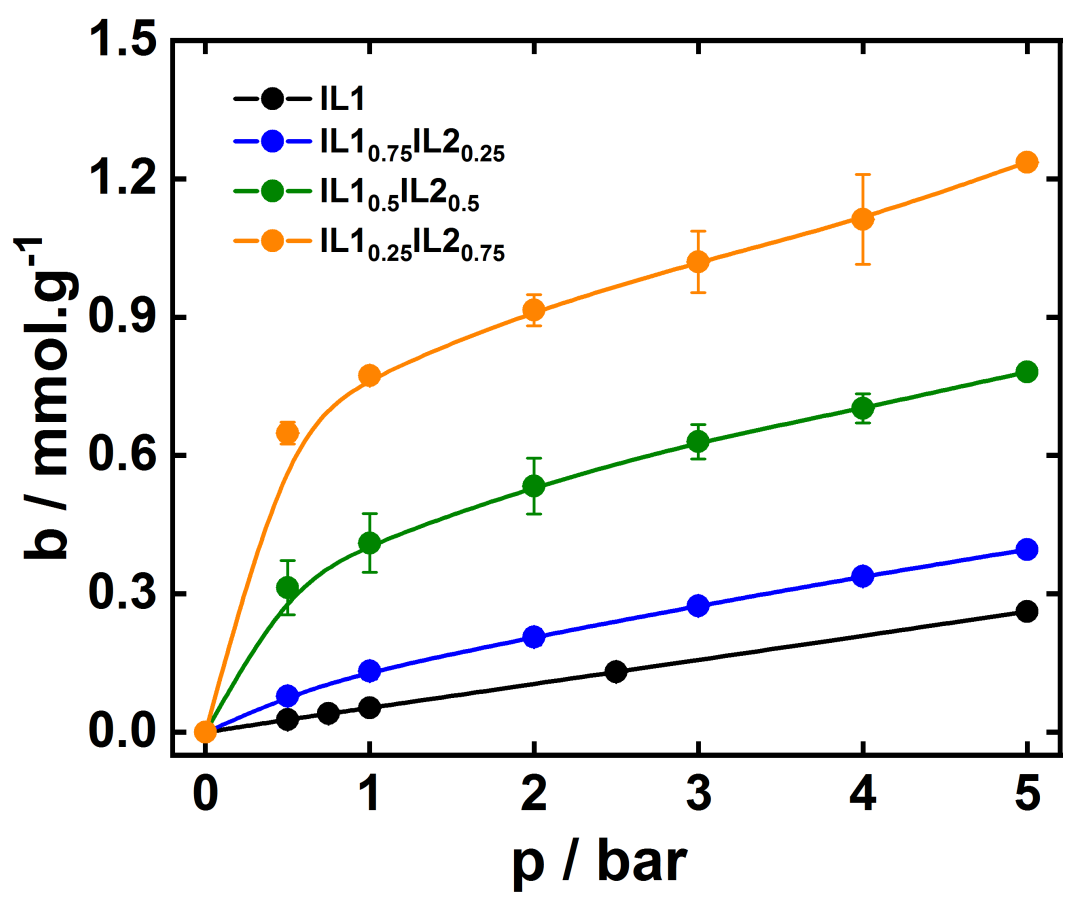

Figure 4: Absorption of $\mathrm{CO}_{2}$ by IL1, IL1 $1_{0.75} \mathrm{IL} 2_{0.25}, \mathrm{IL} 1_{0.5} \mathrm{IL} 2_{0.5}$ and $\mathrm{IL} 1_{0.25} \mathrm{IL} 2_{0.75}$ in the pressure range of $0-5$ bar at $303 \mathrm{~K}$.

$\left[\mathrm{P}_{6,6,6,14}\right]\left[\mathrm{NTf}_{2}\right]+\left[\mathrm{P}_{4,4,4,4}\right][\mathrm{OAc}]$ mixtures ${ }^{6,11}$ and ZIF-8. The suspensions were characterized by measuring their gas absorption capacity and by comparing it to that of the liquid ${ }^{6}$ (represented in Figure 5 and reported in Tables S2-S3). The additional gas capacity attributed to the different MOF concentration in the porous ionic liquids was calculated as previously: ${ }^{6}$

$$
n_{\mathrm{g}}^{\mathrm{MOF}}=n_{\mathrm{g}}^{\mathrm{PL}}-n_{\mathrm{g}}^{\mathrm{IL}}
$$

where, $n_{\mathrm{g}}^{\mathrm{MOF}}, n_{\mathrm{g}}^{\mathrm{PL}}$ and $n_{\mathrm{g}}^{\mathrm{IL}}$ stand for the quantity of gas absorbed by the MOF, the porous liquid and the ionic liquid in the sample, respectively. In a similar way, the relative amount of gas adsorbed by the MOF in the porous liquids relative to that adsorbed in the pure MOF $(\% \beta)$ is calculated as:

$$
\% \beta=\frac{\left(n_{\mathrm{g}}^{\mathrm{MOF}} / m_{\mathrm{s}}\right)}{b_{\mathrm{g}}^{\text {(pureMOF) }}}
$$

where $m_{\mathrm{s}}$ is the mass of the suspension. 
Table 3: MOF content in the porous ionic liquid, quantity of gas absorbed, expected gas absorption for the MOF content, percentage of MOF active to adsorb gas in the porous ionic liquid. All data is at 5 bar and $T=303 \mathrm{~K}$ and $\% \beta$ is related to the experimental absorption, $b_{E x p}$.

\begin{tabular}{|c|c|c|c|c|}
\hline Sample & $\begin{array}{c}\mathrm{MOF} \\
(\% w / w)\end{array}$ & $\begin{array}{c}b_{E x p} \\
\left(\mathrm{mmolg}^{-1}\right)\end{array}$ & $\begin{array}{c}b_{C a l} \\
\left(\mathrm{mmolg}^{-1}\right)\end{array}$ & $\% \beta$ \\
\hline \multicolumn{5}{|c|}{$\mathrm{CO}_{2}$} \\
\hline PoIL1-Z5 & 4.9614 & 0.0995 & 0.1308 & 76 \\
\hline $\operatorname{Po}\left(\operatorname{IL} 1_{0.75} \operatorname{IL}_{0.25}\right)-\mathrm{Z} 5$ & 5.0001 & 0.0210 & 0.1319 & 16 \\
\hline $\mathrm{Po}\left(\mathrm{IL} 1_{0.5} \mathrm{IL} 2_{0.5}\right)-\mathrm{Z} 5$ & 4.9978 & 0.0642 & 0.1319 & 49 \\
\hline $\operatorname{Po}\left(\operatorname{IL} 1_{0.25} \operatorname{IL} 2_{0.75}\right)-\mathrm{Z} 5$ & 5.0239 & 0.0168 & 0.1325 & 13 \\
\hline PoIL3-Z5 & 4.8996 & 0.1373 & 0.1292 & 100 \\
\hline $\mathrm{ZIF}-8$ & 100 & 2.6372 & - & 100 \\
\hline
\end{tabular}

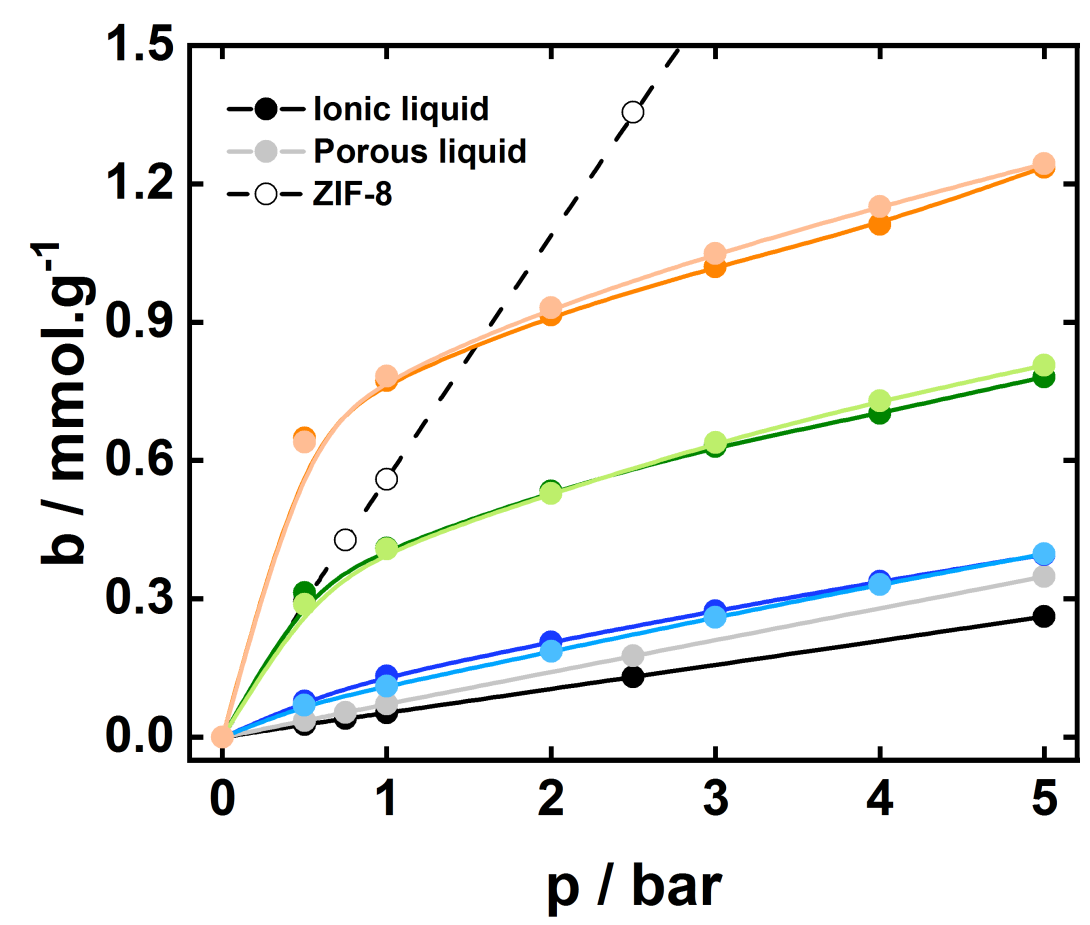

Figure 5: Absorption of $\mathrm{CO}_{2}$ in the pressure range of $0-5$ bar at $303 \mathrm{~K}$ by IL1 (black),

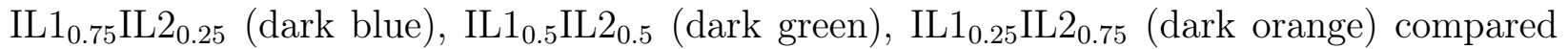
to the porous liquids formed by the addition of ZIF-8 in IL1 and in IL1+IL2 mixtures,

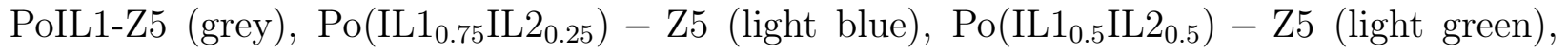
Po(IL1 $\left.1_{0.25} \mathrm{IL}_{0.75}\right)$ - Z5 (light orange) and ZIF-8 (open symbols and dashed line). 
We have shown in our previous work ${ }^{11}$ that the relative increase in the gas physical absorption of porous ionic liquids compared to those of the salts that constitute them depends on the relative amount of MOF suspended, thus proving that the pores of the solid remain free in the suspension. As highlighted in Table 3 (and in Figure 5), this is also observed herein for PoIL1-Z5 which presents an increase in $\mathrm{CO}_{2}$ absorption corresponding to approximately $76 \%$ of the MOF's capacity. However, in the suspensions formed by the ionic liquids mixtures, $\operatorname{Po}\left(\operatorname{IL} 1_{\chi} \operatorname{IL} 2_{1-\chi}\right)$, the relative increase on $\mathrm{CO}_{2}$ absorption compared to that of the $\operatorname{IL} 1_{\chi} \mathrm{IL} 2_{1-\chi}$ mixtures is much lower than the expected capacity based on the quantity of added MOF. A maximum $\% \beta$ of $c a .49 \%$ is found for $\operatorname{Po}\left(\mathrm{IL}_{0.5} \mathrm{IL}_{0.5}\right)$ indicating that the ZIF-8 pores are not fully available to host the gas. ${ }^{11}$ As shown before, ionic liquids based on tetrabutyl phosphonium cations are voluminous enough to stay out of the ZIF-8 pores. The lower than expected $\mathrm{CO}_{2}$ absorption in $\mathrm{Po}\left(\mathrm{IL} 1_{\chi} \mathrm{IL} 2_{1-\chi}\right)$ can only be explained by the presence of acetic acid, a product of the chemical reaction between $\left[\mathrm{P}_{4,4,4,4}\right][\mathrm{OAc}]$ and $\mathrm{CO}_{2}$, which is small enough to enter the pores of ZIF-8.

In order to circumvent other species than the gas from entering the pores in the suspension while maintaining reactivity towards carbon dioxide, we have prepared porous ionic liquids based on salts with larger carboxylate anions. We have maintained the sufficiently voluminous cation $\left(\mathrm{P}_{4,4,4,4}^{+}\right)$and replaced acetate $\left(\mathrm{CH}_{3} \mathrm{COO}^{-}\right)$by levulinate $\left(\mathrm{CH}_{3} \mathrm{CO}\left(\mathrm{CH}_{2}\right)_{2} \mathrm{COO}^{-}\right)$, a considerably larger anion. We obtained a liquid salt at room temperature, $\left[\mathrm{P}_{4,4,4,4}\right][\mathrm{Lev}]$, with a density and a viscosity slightly lower than that of IL1 and that of IL1 $\mathrm{IL}_{1-\chi}$ mixtures with $\chi>0.5$ ( reported in Table S4 and Table S5, respectively).

As in the case of acetate, the levulinate anion also has a carboxylic group able to accept a proton from the $\alpha$-carbon of the tetrabutylphosphonium cation. In presence of $\mathrm{CO}_{2}$, a reaction mechanism similar to that observed for $\left[\mathrm{P}_{4,4,4,4}\right][\mathrm{OAc}]$ (Figure 2) could be expected for $\left[\mathrm{P}_{4,4,4,4}\right][\mathrm{Lev}]$. We have identified other possible reaction paths for $\left[\mathrm{P}_{4,4,4,4}\right][\mathrm{Lev}]$ in presence of $\mathrm{CO}_{2}$ as shown in Figure 6 with carboxylation occurring in the acidic protons on positions 3 and 5 of the levulinate anion. 

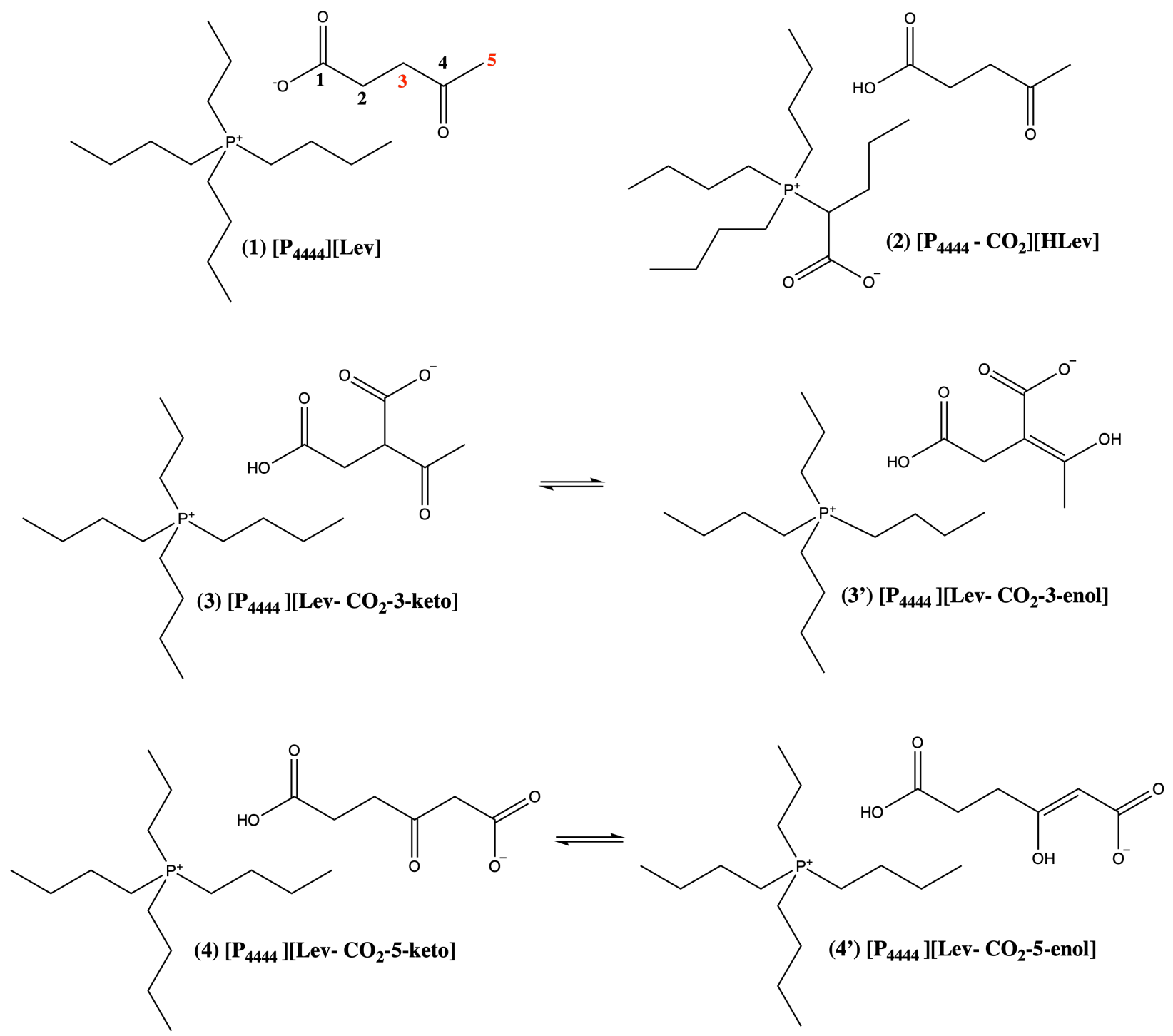

Figure 6: Chemical structure of the $\left[\mathrm{P}_{4,4,4,4}\right][\mathrm{Lev}],(\mathbf{1})$, along with carboxylated species formed after the absorption of $\mathrm{CO}_{2},(\mathbf{2}),(\mathbf{3}),\left(\mathbf{3}^{\prime}\right),(\mathbf{4})$ and $\left(\mathbf{4}^{\prime}\right)$. Numbers in red highlight the acidic protons position of the anion levulinate.

The absorption of $\mathrm{CO}_{2}$ by $\left[\mathrm{P}_{4,4,4,4}\right][\mathrm{Lev}]$ was followed by NMR and FTIR spectroscopy. As with $\left[\mathrm{P}_{4,4,4,4}\right][\mathrm{OAc}]$, the ${ }^{31} \mathrm{P}$ NMR spectrum shows a new peak, corresponding to a new phosphonium species (Figure 7). In addition, three different peaks in the 20-15 ppm region of ${ }^{1} \mathrm{H}$ NMR spectrum show that at least three new carboxylic functions were formed in presence of $\mathrm{CO}_{2}$. Precise analysis of ${ }^{1} \mathrm{H}$ and ${ }^{13} \mathrm{C}$ NMR spectra, together with HSQC, HMBC and COSY 2D NMR experiments led us to consider the formation of several compounds. These compounds correspond to the expected product (2) in Figure 6, formed by the carboxylation 

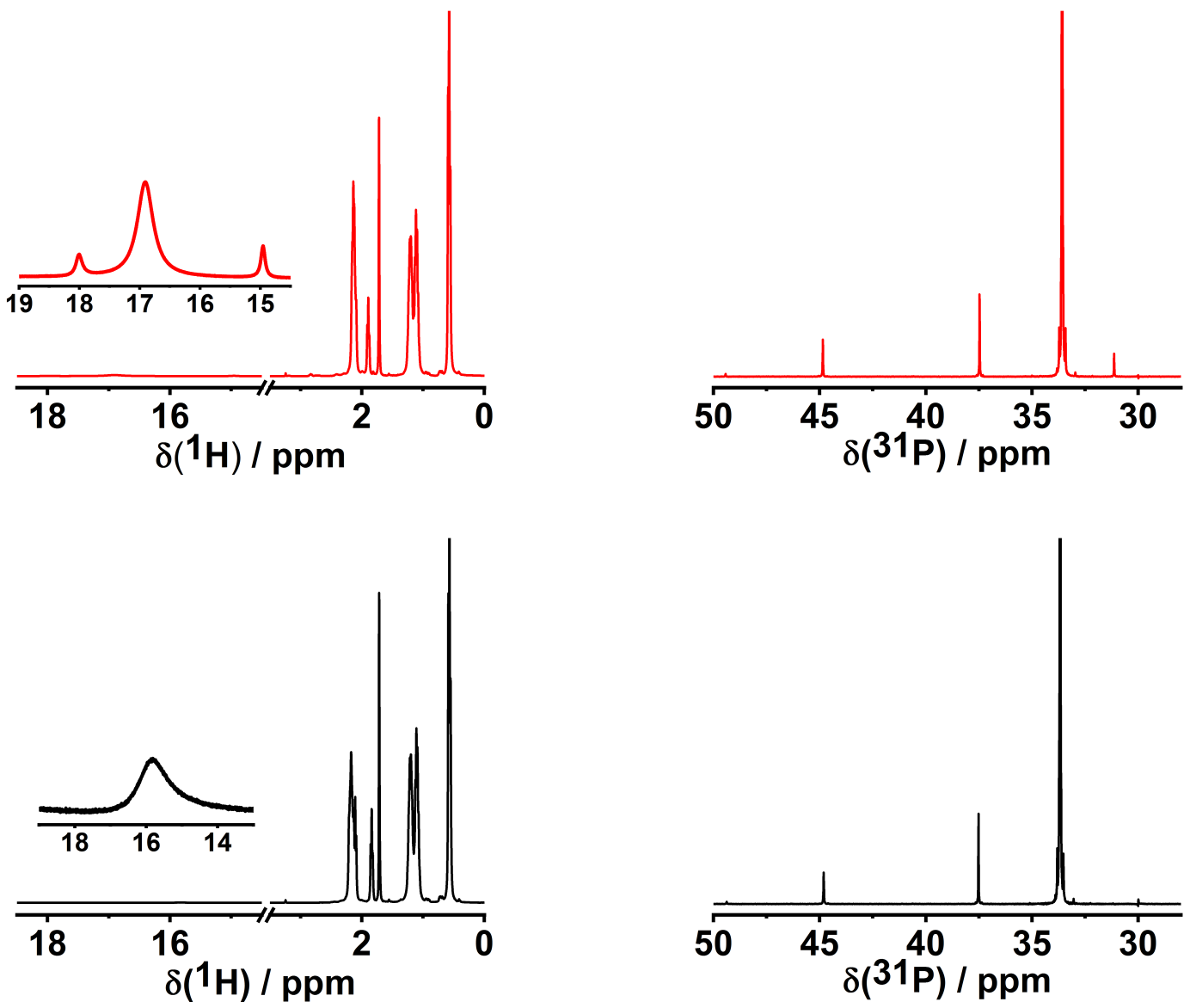

Figure 7: ${ }^{1} \mathrm{H}$ (left) and ${ }^{31} \mathrm{P}$ (right) NMR spectra of $\left[\mathrm{P}_{4,4,4,4}\right][\mathrm{Lev}]$ before (black line) and after (red line) $\mathrm{CO}_{2}$ absorption at $323 \mathrm{~K}$. The ${ }^{1} \mathrm{H}$ highlighted peaks at $c a$. in both spectra corresponds to the acidic protons $(\mathrm{COOH})$ produced. 
of one $\alpha$-carbon of the phosphonium cation, but also to the products of carboxylation of the anion in positions 3 and 5. We suggest the formation of Lev-3- $\mathrm{CO}_{2}$-keto (3) and Lev-5$\mathrm{CO}_{2}$-enol (4') in Figure 6, from $\mathrm{CO}_{2}$ addition at the $\mathrm{C}$-3 position of the anion, and from $\mathrm{CO}_{2}$ addition at the C-5 position followed by the enolisation of the carbonyl group, respectively (details are included in Supplementary Information).

${ }^{1} \mathrm{H}$ NMR spectra of levulinic acid and levulinate anions after carboxylation in different positions were obtained from ab initio calculations (using Gaussian 09, Revision D.01) at the $\mathrm{HF} / 6-311+\mathrm{G}(2 \mathrm{~d} / \mathrm{p})$ level using the GIAO method in an implicit solvent of relative permittivity 20.7. The geometries were previously optimized at the B3LYP/6-31G(d) level, in the same implicit solvent. The nature of the three acid proton peaks observed experimentally in the chemical shift range of $15-20 \mathrm{ppm}$ (as seen in Figure 7) could be confirmed as depicted in Figure S25. The different positions of the carboxylation were considered as well as the keto-enolic equilibrium. Even if the simulation did not take into account the cation, $\left[\mathrm{P}_{4,4,4,4}\right]^{+}$ and the dissolved $\mathrm{CO}_{2}$, it clearly shows the existence of intramolecular hydrogen bonding involving the $-\mathrm{COOH}$ and $\mathrm{OH}$ groups in the anion. The presence of this hydrogen bonds leads to the de-shielding of the protons involved and confirms the possibility of carboxylation of different sites of the anion.

FTIR spectroscopy of $\left[\mathrm{P}_{4,4,4,4}\right][\mathrm{Lev}]$ with different $\mathrm{CO}_{2}$ pressures and contact times between the gas and the ionic liquid confirmed the apparition of new $\mathrm{O}-\mathrm{H}, \mathrm{C}=\mathrm{C}$ and $\mathrm{C}=\mathrm{O}$ bonds, in accordance with the formation of Lev-3- $\mathrm{CO}_{2}$-keto and Lev-5- $\mathrm{CO}_{2}$-enol considered after NMR analysis (details in Supplementary Information).

The chemical absorption of carbon dioxide by $\left[\mathrm{P}_{4,4,4,4}\right][\mathrm{Lev}]$ is clearly shown in the isotherm at $303 \mathrm{~K}$ depicted in Figure 8, as the gas absorption does not vary linearly with pressure. The capacity of $\left[\mathrm{P}_{4,4,4,4}\right][\mathrm{Lev}]$ to reversibly absorb $\mathrm{CO}_{2}$ is remarkable, especially at low pressures (bellow 2 bar) where it exceeds that of the pure MOF by more than $100 \%$ at $303 \mathrm{~K}$.

When $5 \% \mathrm{w} / \mathrm{w}$ of ZIF-8 is suspended in $\left[\mathrm{P}_{4,4,4,4}[\mathrm{Lev}]\right.$ to form the porous liquid PoIL3-Z5, the $\mathrm{CO}_{2}$ absorption capacity is further enlarged, its relative increase being correlated with 


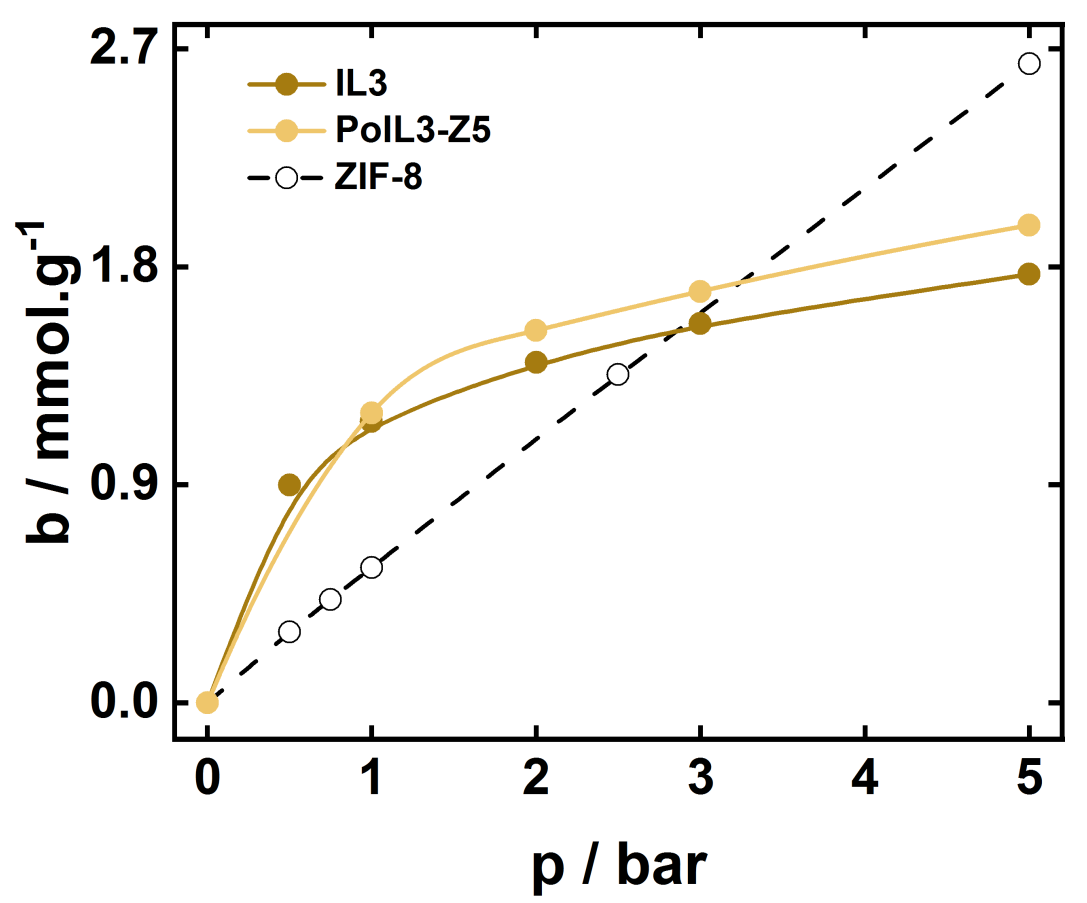

Figure 8: Absorption of $\mathrm{CO}_{2}$ by IL3, PoIL3-Z5 and ZIF-8 in the pressure range of $0-5$ bar at $303 \mathrm{~K}$.

the MOF concentration. As seen in Table 3, all the pores of the solid in this suspension are available to absorb gas, PoIL3-Z5 presenting a $\% \beta$ of $c a .100 \%$. This observation confirms that the molar volume of the species in the reaction medium is important, the levulinic acid as well as the $\mathrm{CO}_{2}$-anion aducts formed being voluminous enough to not enter the pores of the suspended solid.

As previously reported, the volume of the ion pairs used to form type III porous ionic liquids with ZIF-8 should be high enough to prevent pore obstruction in the liquid. ${ }^{6,11}$ Herein, we have shown that the volume of the species formed when these materials are used as reaction media must also be considered. The species in solution must be sufficiently voluminous to remain out of the pores in the liquid that are then free to adsorb gas. The MOF must also be chosen carefully as shown in our previous work ${ }^{6}$ to allow the formation of stable suspensions and to maintain permanent porosity in the liquid.

The porous liquid formed by the $\left[\mathrm{P}_{4,4,4,4}\right][\mathrm{Lev}]$ and ZIF-8 is, up to now, the most per- 
formant fluid porous ionic liquid for absorbing $\mathrm{CO}_{2}$ at low pressure with a capacity of $1.5 \mathrm{mmol} \mathrm{g}^{-1}$ at $303 \mathrm{~K}$ and 2 bar, similar to those of currently used sorbent materials such as ethanolamines $\left(\approx 1.8 \mathrm{mmol} \mathrm{g}^{-1}\right.$ for N-ethyl-diethanolamine at $40^{\circ} \mathrm{C}$ and $\left.1 \mathrm{bar}^{24}\right)$ or other solid amine sorbents $\left(2.6 \mathrm{mmol} \mathrm{g}^{-1}\right.$ for mesoporous silica decorated with polyethylenimine at $30^{\circ} \mathrm{C}$ and $\left.1 \mathrm{bar}^{24}\right)$.

\section{Conclusion}

We have shown that it is possible to form porous ionic liquids that capture large quantities of carbon dioxide reversibly and at low pressure. When sufficiently voluminous ionic liquids are chosen, carbon dioxide absorption is intensified by the presence of permanent pores in the liquid. The ionic liquids can be engineered to chemically absorb carbon dioxide namely through the use of phosphonium carboxylate salts. The mechanisms of the $\mathrm{CO}_{2}$ chemical absorption were analysed in detail and point towards the use of these ionic liquids as a promising route to prepare efficient and stable porous liquids for low pressure carbon capture.

We present herein a real alternative to the use of aqueous amines for low pressure $\mathrm{CO}_{2}$ capture in absorption processes. The use of porous ionic liquids present the advantages of using a non-volatile, thermally stable and non-corrosive liquid absorbent that does not require a solvent and with performances at low pressures similar to those of the currently used aqueous amines. Furthermore, the preparation of porous ionic liquids is easy and can be done from off-the-shelf well characterised and readily available metal organic frameworks and ionic liquids. The approach described makes use of the most attractive features of both MOFs and ionic liquids: in the former, the ability to choose the metal, the organic linker and the pore size, and in the latter the tuning of the physical and chemical properties of the liquid salt through proper pairing of anions and cations, including reactive groups. 


\section{Acknowledgement}

M.C.G. and J.A. thank IDEX-LYON for financial support (Programme Investissements d'Avenir ANR-16-IDEX-0005).

\section{Supporting Information Available}

Experimental procedures, characterization and spectral data (ATR FTIR and NMR). Numerical data in absorption measurements, density and viscosity. 


\section{References}

(1) O’Reilly, N.; Giri, N.; James, S. L. Porous liquids. Chem. - A Eur. J. 2007, 13, 30203025.

(2) Giri, N.; Del Pópolo, M. G.; Melaugh, G.; Greenaway, R. L.; Rätzke, K.; Koschine, T.; Pison, L.; Gomes, M. F.; Cooper, A. I.; James, S. L. Liquids with permanent porosity. Nature 2015, 527, 216-220.

(3) Zhang, J.; Chai, S. H.; Qiao, Z. A.; Mahurin, S. M.; Chen, J.; Fang, Y.; Wan, S.; Nelson, K.; Zhang, P.; Dai, S. Porous liquids: A promising class of media for gas separation. Angew. Chemie - Int. Ed. 2015, 54, 932-936.

(4) Zhang, F.; Yang, F.; Huang, J.; Sumpter, B. G.; Qiao, R. Thermodynamics and Kinetics of Gas Storage in Porous Liquids. J. Phys. Chem. B 2016, 120, 7195-7200.

(5) Kearsey, R. J.; Alston, B. M.; Briggs, M. E.; Greenaway, R. L.; Cooper, A. I. Accelerated robotic discovery of type II porous liquids. Chem. Sci. 2019,

(6) Costa Gomes, M.; Pison, L.; Červinka, C.; Padua, A. Porous Ionic Liquids or Liquid Metal-Organic Frameworks? Angew. Chemie - Int. Ed. 2018, 57, 11909-11912.

(7) Li, P.; Chen, H.; Schott, J. A.; Li, B.; Zheng, Y.; Mahurin, S. M.; Jiang, D. E.; Cui, G.; Hu, X.; Wang, Y.; Li, L.; Dai, S. Porous liquid zeolites: Hydrogen bonding-stabilized H-ZSM-5 in branched ionic liquids. Nanoscale 2019, 11, 1515-1519.

(8) Shan, W.; Fulvio, P. F.; Kong, L.; Schott, J. A.; Do-Thanh, C. L.; Tian, T.; Hu, X.; Mahurin, S. M.; Xing, H.; Dai, S. New Class of Type III Porous Liquids: A Promising Platform for Rational Adjustment of Gas Sorption Behavior. ACS Appl. Mater. Interfaces 2018, 10, 32-36.

(9) Bavykina, A.; Cadiau, A.; Gascon, J. Porous liquids based on porous cages, metal 
organic frameworks and metal organic polyhedra. Coord. Chem. Rev. 2019, 386, 8595.

(10) Liu, S.; Liu, J.; Hou, X.; Xu, T.; Tong, J.; Zhang, J.; Ye, B.; Liu, B. Porous Liquid: A Stable ZIF-8 Colloid in Ionic Liquid with Permanent Porosity. Langmuir 2018, 34, $3654-3660$.

(11) Avila, J.; Cervinka, C.; Dugas, P.-Y.; Padua, A.; Costa Gomes, M. Porous ionic liquids: structure, stability and gas absorption mechanisms. Submitted

(12) Sheridan, Q. R.; Schneider, W. F.; Maginn, E. J. Role of Molecular Modeling in the Development of CO2-Reactive Ionic Liquids. Chem. Rev. 2018, 118, 5242-5260.

(13) Shiflett, M. B.; Drew, D. W.; Cantini, R. A.; Yokozeki, A. Carbon dioxide capture using ionic liquid 1-butyl-3-methylimidazolium acetate. Energy and Fuels 2010, 24, $5781-5789$.

(14) Bates, E. D.; Mayton, R. D.; Ntai, I.; Davis, J. H. CO 2Capture by a Task-Specific Ionic Liquid. J. Am. Chem. Soc. 2002, 124, 926-927.

(15) Gurkan, B. E.; de la Fuente, J. C.; Mindrup, E. M.; Ficke, L. E.; Goodrich, B. F.; Price, E. A.; Schneider, W. F.; Brennecke, J. F. Equimolar CO 2Absorption by AnionFunctionalized Ionic Liquids. J. Am. Chem. Soc. 2010, 132, 2116-2117.

(16) Gurau, G.; Rodríguez, H.; Kelley, S. P.; Janiczek, P.; Kalb, R. S.; Rogers, R. D. Demonstration of chemisorption of carbon dioxide in 1,3-dialkylimidazolium acetate ionic liquids. Angew. Chemie - Int. Ed. 2011, 50, 12024-12026.

(17) Stevanovic, S.; Podgoršek, A.; Pádua, A. A.; Costa Gomes, M. F. Effect of water on the carbon dioxide absorption by 1-alkyl-3- methylimidazolium acetate ionic liquids. $J$. Phys. Chem. B 2012, 116, 14416-14425. 
(18) Bui, M. et al. Carbon capture and storage (CCS): The way forward. Energy Environ. Sci. 2018, 11, 1062-1176.

(19) Gohndrone, T. R.; Bum Lee, T.; Desilva, M. A.; Quiroz-Guzman, M.; Schneider, W. F.; Brennecke, J. F. Competing reactions of CO2 with cations and anions in azolide ionic liquids. ChemSusChem 2014, 7, 1970-1975.

(20) Yang, Q.; Xu, D.; Zhang, J.; Zhu, Y.; Zhang, Z.; Qian, C.; Ren, Q.; Xing, H. Long-Chain Fatty Acid-Based Phosphonium Ionic Liquids with Strong Hydrogen-Bond Basicity and Good Lipophilicity: Synthesis, Characterization, and Application in Extraction. ACS Sustain. Chem. Eng. 2015, 3, 309-316.

(21) Lee, T. B.; Oh, S.; Gohndrone, T. R.; Morales-Collazo, O.; Seo, S.; Brennecke, J. F.; Schneider, W. F. CO2 Chemistry of Phenolate-Based Ionic Liquids. J. Phys. Chem. B 2016, 120, 1509-1517.

(22) Firaha, D. S.; Gibalova, A. V.; Hollóczki, O. Basic Phosphonium Ionic Liquids as Wittig Reagents. ACS Omega 2017, 2, 2901-2911.

(23) Macarie, L.; Simulescu, V.; Ilia, G. Phosphonium-Based Ionic Liquids Used as Reagents or Catalysts. ChemistrySelect 2019, 4, 9285-9299.

(24) Dutcher, B.; Fan, M.; Russell, A. G. Amine-based CO2 capture technology development from the beginning of 2013-A review. ACS Appl. Mater. Interfaces 2015, 7, 2137-2148. 